\title{
Special at school but lonely at home: An alternative friendship group for adolescents with Down syndrome
}

\section{Jeanne D'Haem}

Friends play a significant role in mental and physical health; however, individuals with Down syndrome and other developmental disabilities, even those who are included in general education programmes, have not developed friendships as hoped. After a decade of inclusion and structured school programmes to facilitate friendships, many parents report that peer relationships end after school hours. This study compared the efficacy of school based friendship groups with a mixed age home based group. Specific methods to establish a successful friendship group are discussed. This study followed three friendship groups for five years. Two groups of six to eight general education students met with the target student twice a month during the school day; one group of mixed age participants met in the student's home. A counsellor facilitated all the groups. Parent and student concerns regarding friendships were informally assessed with interviews and observations. Observations and interviews confirmed that although peer interactions during school occurred they did not continue after school. Of the three students studied, only one had a relationship with a same-aged peer after four years of school facilitated groups. Two students had significant feelings of depression during high school. One student entered counselling. The home-based mixed age friendship group did result in significant friendships. The individual participated in two or three activities each month with friends from the group. School based friendship groups of adolescent peers were not successful in developing friendships for individuals with Down syndrome. When a multi-age group was conducted outside of the school, friendships formed and have continued for over two years. This article describes how and why parents and professionals should look beyond school based same age peer friendship groups and consider a community circle of mixed-age friends.

\section{"Friends don't have to be our age - friends are peo- ple who like you."}

Making friends is one of the most intractable problems for children with significant special needs - some do not have a single person who is their friend. Many research studies ${ }^{[1-4]}$ have found that friends play a significant role in mental and physical health; however, developing friendships remains a problem for those with Down syndrome and other developmental disabilities. Peer relations are a critical aspect of a child's life ${ }^{[5]}$. Most importantly, in order for individuals with developmental disabilities to live independent and full lives, friends in the community are critical. The possibility of community friend- ships has been a major impetus for the full inclusion of individuals with severe disabilities in local public schools. However, according to Myra Madnick, the former Executive Director of the National Down Syndrome Society in New York, "Despite all of the gains individuals with Down syndrome have made, loneliness is a major problem." Although students who are included have made great strides in language, behavior, social development and academics this is not true for social inclusion ${ }^{[6]}$.

Many schools have established Circle of Friends groups in order to facilitate social acceptance and friendships for children with disabilities; however, in this study of five years of group meetings, 
relationships did not continue outside of school. This study followed two students with Down syndrome and one with other developmental disabilities for five years. The students attended a mixture of general and special education classes at their local public schools. Three Circle of Friends groups were established in elementary or middle school to facilitate friendships for each student. Six same-age peers from the general population met with the target student twice a month during the school year. A social worker, guidance counsellor, or school psychologist facilitated the groups. Although acceptance during the school day was excellent, peer relationships did not continue outside of the structured school day. Of the three students studied, only one had a relationship with a peer after four years of facilitated groups. Friendships are especially important during secondary school as they provide support previously given by parents ${ }^{[7,11]}$; however, the structured friendship groups established for the students in this study had to be discontinued during secondary school. All three groups were disbanded in the upper grades due to difficulties in getting peers to participate.

Once the target student entered secondary school friendship groups could not be scheduled during the school day. Teachers were not willing to release students from their classes so they could attend friendship group sessions and students were also concerned about missing instruction. Although many students reported continued interest in the project and were willing to meet with the target students they were not interested in meeting during lunch. These secondary students do not have free periods during the day and most were active in sports and clubs after school. After several months of attempts to schedule a mutually beneficial time to meet the in-school friendship group meetings had to be abandoned.

Older students may not be interested in structured peer-support programmes for students with developmental disabilities because they are teacher directed ${ }^{[8]}$. Intervention has been found to be more successful when peer ownership, and problem solving were emphasised over teachermediated strategies ${ }^{[9,10,12,13]}$. For one of the students in this study, the group facilitator attempted to mediate informal meetings between the target student and peers from the secondary school for after school meetings at a local teashop; however these were also unsuccessful and did not occur.

"Nobody ever wants to hang out with me because I have Down syndrome." Alice, age 17

Alice was a secondary school student with Down syndrome. The efforts to establish a circle of friends in the secondary school failed for her and

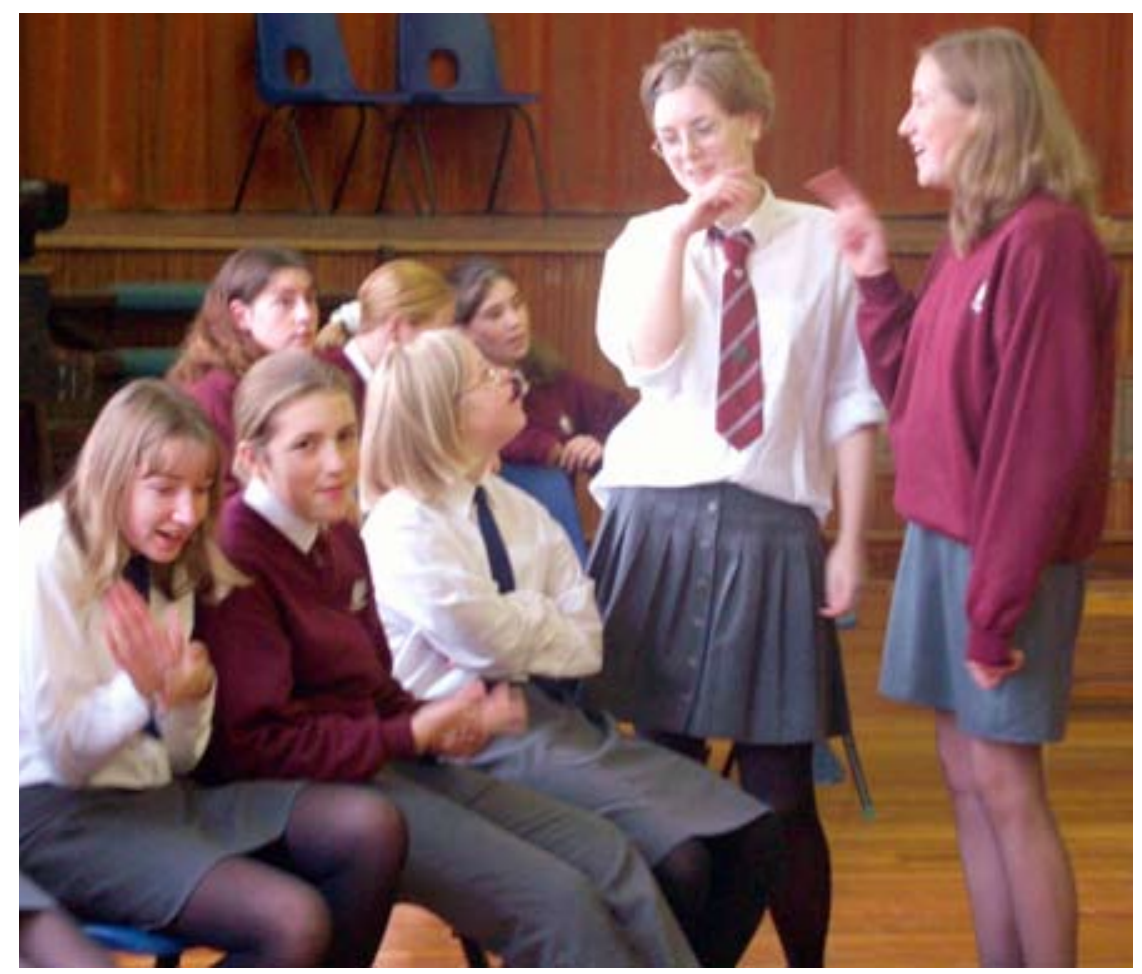

\section{Making friends is one of the most intractable problems for} children with significant special needs.

her mother reported, "I'm worried about Alice. At the dinner table everyone talked about his or her weekend plans. My husband and I are having dinner with another couple on Saturday night, and Brittany is going to the mall with her girlfriends, Scarlett and Ally. I happened to glance over at Alice and her head was practically on the table."

When asked what was wrong, Alice whispered, "Nobody ever wants to hang out with me because I have Down syndrome."

Alice had been in general education classes since first grade. Her parents did not want her

\section{Box 1 | Community Circle of Friends}

- Information about a Circle of Friends is available on the web. Some excellent sites include: www.inclusive-solutions.com, www.ECAC-parentcenter.org, www. udel.edu

- Make sure that the student would like to start a circle - not everyone is interested in being the centre of attention. The key to a successful Circle of Friends is the student's and the friend's ownership of the experience.

- Meet with the student's parents and explain the programme. Offer to facilitate the first few meetings.

- Ask your student to list people he or she likes in the family, the neighbourhood or at school (or work), both adults and kids. We are close to people who share our ideas and interests regardless of age. Many young people with handicaps actually prefer the company of adults - respect this.

- The special and general education teachers may have names of students who would like to be included.

- See if there is anyone who would be good at running the meeting if you are not comfortable doing so. Many people are used to a leadership role at work or in volunteer positions. 


\section{Box 2 | Steps to start a Community Circle of Friends}

1. Send out invitations or make some phone calls.

2. Two hours is a good amount of time.

3. Have the meeting in a private home, the church basement, or a local pizza parlour.

4. The special education teacher should help the student draw up a list of things they like to do. Parents should add to the list and help the student to practise saying it.

5. The student should practise greetings, hanging up coats and offering refreshments. Begin this in class and ask the parent to practise the same routine at home so the student responds to the doorbell, is comfortable opening the door and hanging up coats and knows how to hand someone food and drink.

to be placed in a separate class or school for children with cognitive impairments. They wanted her to be accepted by people in the community where she lives. Teachers attended training sessions, an instructional aide was hired and Alice quickly learned to hang up her coat and sit on the rug for the morning circle.

Alice attended a public secondary school. She took some general classes with the assistance of an instructional aide who modified assignments for her. She had reading and maths classes in special education with students who have learning disabilities. She went from class to class on her own, opened her locker, changed for gym and bought lunch in the cafeteria. She helped to manage the field hockey team and danced in the school play. Her high school teachers reported that she pays attention in class and does every scrap of homework.

No one stared at or teased Alice, it was clear that she was accepted at the secondary school but she did not have a single friend. She came to the homecoming dance and a few girls said hello but it was painful to watch her standing alone listening to the music. The secondary students

\section{Box $3 \mid$ The Meetings}

1. The student greets everyone, takes their coat and offers refreshments.

2. The facilitator will go around the room and ask everyone to introduce themselves and tell how they know the student.

3. Ask the student to talk about his or her interests. It is critical to allow the student to express their own interests; they must be respected.

4. Ask the circle members to talk about what they have been doing and any interests or hobbies they have. Look for connections between what the circle members like to do and what the student likes to do.

5. If people would like to set up some activities that should happen naturally. No one should feel forced to do something.

6. Always allow the student to agree, delay, or decline an offer to do something. They must be in control.

7. Choose a date for the next meeting usually no more than every other month.

8. The student may want to cook dinner, rent a video, or celebrate birthdays at the following meetings. were kind and protective, but they did not call to chat on the phone or invite her to hang out at the mall.

When the school bus dropped her off at home, Alice got off the social circuit as well.

During Alice's intermediate school years, her special education case manager organised a Circle of Friends at school. Student volunteers were released from class to meet with Alice and her social worker. The girls got to know Alice and helped her with her locker and greeted her in the hall. The volunteers were selected so she had a friend in every class. They had in-school parties for her birthday and Alice sat with them at lunch. When she entered high school a circle of friends was difficult to schedule because students could not miss classes. Student leaders were asked to get involved with Alice informally. They were eager to help during school, but no one called Alice to see a movie or asked for her e-mail address.

When the bus dropped her off at home, Alice got off the social circuit as well.

The inclusion programme worked for Alice within the structure of the school day. She acted like a high school student; she dressed like a typical teen and was liked by the other students. Although Alice had a normal school day she was lonely and unhappy at home.

\section{From the invitation to the community circle:}

Alice understands that to live independently she will need the support of people in the community, her friends, her parents, siblings and other relatives. The hope with inclusion is to foster these relationships now so the supports are in place later. Alice also needs to learn how to initiate and maintain friendships.

Since a major goal of the friendship programme had not been met, the in-school friendship groups were reconsidered. Interest in the formal friendship circles declined in secondary school and the target students did not develop sustained friendships with peers. Two students reported feelings of unhappiness and parents reported concerns about depression. One family sought counselling for their daughter. Attempts to nurture a more student directed, less professionally facilitated programme for Alice also failed.

An inclusion specialist from the New Jersey State Department of Education, Peggy Thorpe, suggested moving the Circle of Friends out of the school and into the community. Thorpe suggested that one issue might be the idea that friends must be the same age as the target student. She pointed out that friends don't have to be our age - friends are people who like you. We also wondered if peer participation would increase with more control of the interventions by the participants instead of a facilitator ${ }^{[8,9]}$. Although the secondary school 
students always indicated that they were interested in friendships with students with Down syndrome, they avoided teacher directed interventions or suggestions from counsellors about what they should do to assist the student with Down syndrome. The intervention team wondered if students would respond to a mixed age group where they would be equal participants in problem solving along with the adults.

Alice's parents liked the idea and were willing to try. In order to establish a community circle, Alice and her mother compiled a list of the people, young and old, neighbours and relatives, church members and business associates, whom Alice liked (see BOX 1). Alice and her mother decided to have the circle meet at their home instead of at the school. They composed an invitation for the first meeting. This paragraph was in the invitation:

Alice understands that to live independently she will need the support of people in the community, her friends, her parents, siblings and other relatives. The hope with inclusion is to foster these relationships now so the supports are in place later. Alice also needs to learn how to initiate and maintain friendships.

Ten people were present at the first Community Circle meeting. Participants included Alice's parents, her sister and her two best friends, an aunt, a friend from school, the youth pastor from her church, a family friend from her father's business, and me. Alice greeted everyone at the door and helped to serve pizza and soft drinks (see BOX 2).

The inclusion specialist had agreed to facilitate the first few meetings. She asked everyone in the circle to introduce themselves and tell how they knew Alice. The group talked about friends and the adults and young adults developed a definition.

A friend is someone who:

- you feel comfortable telling your secrets

- you go places and do things with

- enjoys the same things as you do

- notices when you are not feeling right

The facilitator asked everyone to share things they liked to do. Scott is active at the local firehouse, Scarlett likes to figure skate, watch movies and dance. Alice likes to eat out, watch movies and figure skate.

Alice shared her dreams and how she hopes to accomplish them. She would like to work with children someday and live near her parents. She wants to do more volunteering in the community, perhaps through the church. As the group shared their interests and Alice talked about her goals, connections began to emerge. The youth

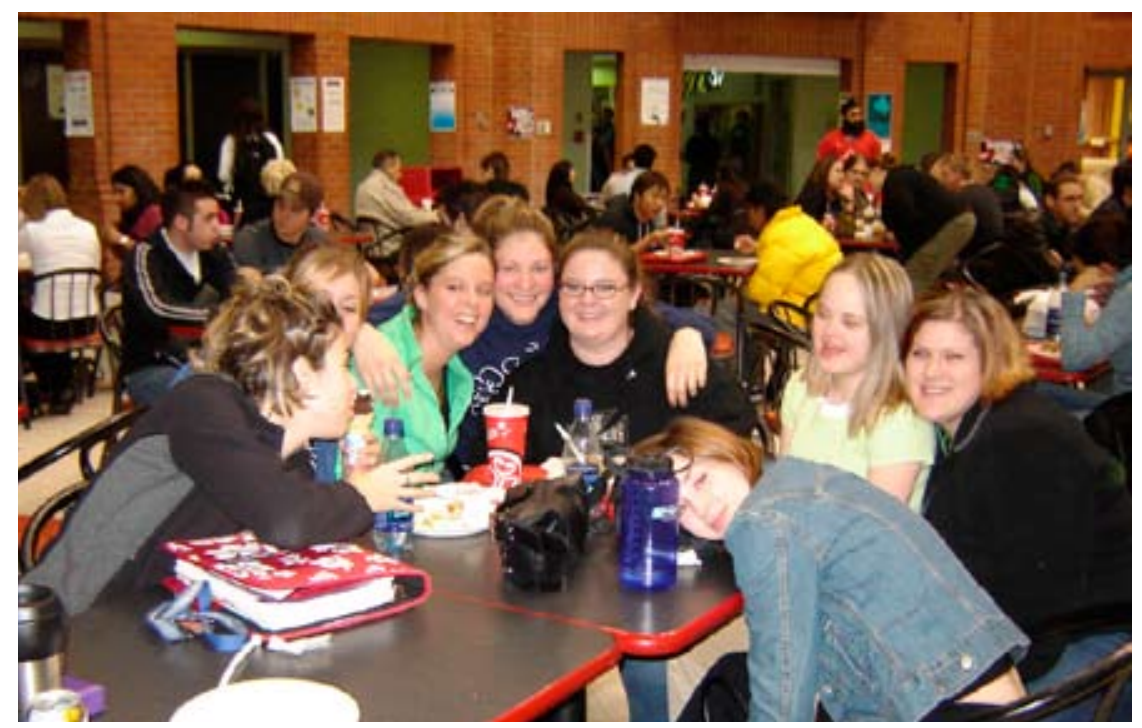

In order for individuals with developmental disabilities to live independent and full lives, friends in the community are critical.

minister asked Alice to attend a church volunteer project. One of the girls asked Alice to her house to get dressed for the junior prom. Alice's sister took notes.

Alice wrote about her Community Circle:

There is a Community Circle of Friends that I started with some help from my mother and Dr. D'Haem. We started by deciding on a place to have it. My mother and I decided to have it at my home. I invited friends from church, school and the community. The first thing we do in the circle is to go around the room and tell what we have done in the last month or two. I either make dinner or order the food. The next thing that we do is to think about and make goals for me. I feel that the community circle is good for me. I go out with my friends, go to a movie, or go over to someone's house and have fun. I feel I have friends that want to get to know me. To tell you the truth, I love having a circle of friends. It is a way for us to get to know and trust each other. To sum it up, if people don't want to get to know me - that is too bad. They will miss out on knowing a great interesting girl.

The Community Circle of Friends met every other month for almost two years. Alice learned how to send out invitations and cooked dinner for one meeting. She knows how to invite someone over who has shown an interest in her. She knows how to greet friends at the door and make them feel welcome (see BOX 3).

Alice no longer needs a formal Community Circle of Friends. Scarlett e-mails from college at least once a week and they always make plans to do something together when she comes home for a holiday. Alice and her aunt take a yoga class together. She remains active in volunteer projects at her church and spent a week in Maine helping to fix up a house with a church group.

Community Circles were suggested to two 
other students with developmental disabilities when they entered high school. One student attended Alice's Circle meeting with her mother. Although her parents were very interested in the concept, the student did not want to participate. At this point she felt content with the activities and relationships offered by her family. The other student's parents felt that their child would form friendships after high school in the work environment.

\section{Conclusion}

The important goal in a Community Circle of Friends is that all parties gain something from the friendship. Secondary students may not be interested in participation in adult led friendship groups. They may however, be active participants in mixed age groups where they are full members with adults. The community-centred group is a good transition to the adult world where friends are not people who are the same age, but people with similar interests. Individuals with Down syndrome and other developmental disabilities have a lot to offer in their own unique way. Community Circles for the other two students in this study might have been successful if a transition programme had been in place from the beginning of the friendship circles, in school groups for primary and intermediate school and a community based group during secondary school.
1. Berndt TJ. Contributions of peer relationships to child development. In Berndt TJ and Ladd GW, editors. Peer Relationships in Child Development. New York: Wiley and Sons; 1989: p. 407-416.

2. Buhrmester D, Furman W. The development of companionship and intimacy. Child Development. 1987;58:1101-1113.

3. Farmer TW, Farmer EM. Social relationships of students with exceptionalities in mainstream classroom: Social networks and homophily. Exceptional Children. 1996;62:431-450.

4. Pavri S, Monda-Amaya L. Social support in inclusive schools: Student and teacher perspectives. Exceptional Children. 2001;67:391-411.

5. Williams SL, Walker HM, Holmes D, Todis B, Fabre TR. Social validation of adolescent social skills by teachers and students. Remedial and Special Education. 1989;10:18-27.

6. Buckley S, Bird G, Sacks B, Archer T. A comparison of mainstream and special education for teenagers with Down syndrome: implications for parents and teachers. Down Syndrome News and Update. 2005;2(2):46-54.

7. Zetlin AG, Murtaugh M. Friendship patterns of mildly learning handicapped and nonhandicapped high school students. American Journal on Mental Retardation. 1988;92:447-453.

8. Chadsey J, Kyoung GH. Friendship-facilitation strategies: what do students in middle school tell us? Teaching Exceptional Children. 2005;38: 52-57.

9. Haring TG, Breen KG. A peer mediated social network intervention to enhance the social integration of persons with moderate and severe disabilities. Journal of Applied Behavior Analysis. 2003;25:319-333.

10. Kolb S, Hanley-Maxwell C. Critical social skills for adolescents with high incidence disabilities: parental perspectives. Exceptional Children. 2003;69:163-179.
11. Panacek $L$, Dunlap $G$. The social lives of children with emotional and behavioral disorders in selfcontained classrooms: A descriptive analysis. Exceptional Children. 2003;69:333-348.

12. Vincent $C$, Horner R, Sugai G. Developing Social Competence for All Students. The Vision - NJCIE. 2002; Fall: 8-10.

13. McVilly K, Stancliffe R, Parmenter T, BurtonSmith R. 'I get by with a little help from my friends': Adults with intellectual disability discuss loneliness. Journal of Applied Research in Intellectual Disabilities. 2006;19(2):191-203.

Received: 27 November 2006; Accepted 14 February 2007; Published online: 28 August 2007.

doi: 10.3104/updates.2012

\section{Best Buddies}

Below are some quick facts about Best Buddies history, mission, international growth, and developments in the UK.

- Best Buddies ${ }^{\circledast}$ is a nonprofit 501(c)(3) organisation dedicated to enhancing the lives of people with intellectual disabilities by providing opportunities for one-to-one friendships and integrated employment.

- Founded in 1989 by Anthony K. Shriver, Best Buddies is a vibrant, international organisation that has grown from one original chapter at Georgetown University to more than 1,200 middle school, high school, and college campuses across the country and internationally. We impact the lives of 300,000 people each year.

- The organisation is active in each of the 50 United States, and operates accredited international programs in Australia, Brazil, Canada, Colombia, Cuba, Ecuador, Egypt, England, Germany, Ghana, Honduras, Hong Kong, Ireland, Israel, Kenya, Mexico, the Netherlands, New Zealand, Panama, the Philippines, Saudi Arabia, Scotland, Singapore, Spain, Sweden, Tanzania, Thailand, and the United Arab Emirates - with additional country programmes in advanced phases of development. By 2010, Best Buddies will continue to build on its successful volunteer base in all 50 States, further expand its accredited international programmes to 50 countries and annually engage more than 500,000 people worldwide.
-We have six programmes: Best Buddies Middle Schools, Best Buddies High Schools, Best Buddies Colleges, Best Buddies Jobs, Citizens, and e-Buddies. Student/Citizen volunteers are matched with 'Buddies,' individuals with intellectual disabilities.

\section{UK Developments:}

- Best Buddies Scotland enjoys an exciting partnership with Enable Scotland. Two university chapters exist, at The University of Glasgow (1st year programme), and The University of Stirling (3rd year programme). Contact Lena Gillies, lena.gillies@enable. org.uk.

- Best Buddies England is in partnership with Mencap and is in the development stages. School programmes with matched volunteers will launch in Autumn 2007.

For more information on international programmes, or developments in the UK, please contact Valerie Vitale, International Programs Director, at ValerieVitale@bestbuddies.org

Ashley Glesser 